a. Overall Survial PDS cohort

CD8CD103 TRM tumor epithelial infiltration
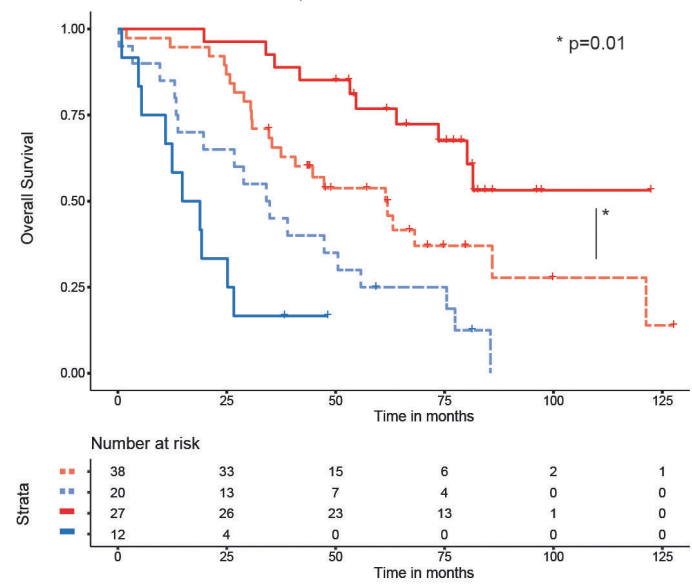

c. Overall Survival NACT cohort

CD8CD103 TRM tumor epithelial infiltration
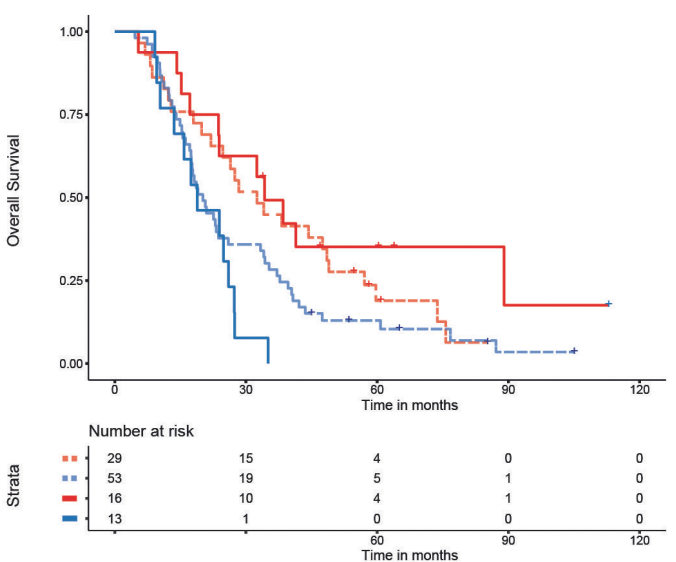

1=1= Low CD8CD103 infiltration + No macroscopic leasions post-surgery

High CD8CD103 infiltration + No macroscopic leasions post-surgery

=-1= Low CD8CD103 infiltration + Macroscopic leasions post-surgery

High CD8CD103 infiltration + Macroscop leasions post-surgery b. Overall Survival PDS cohort

CD8CD103 TRM Stromal infiltration
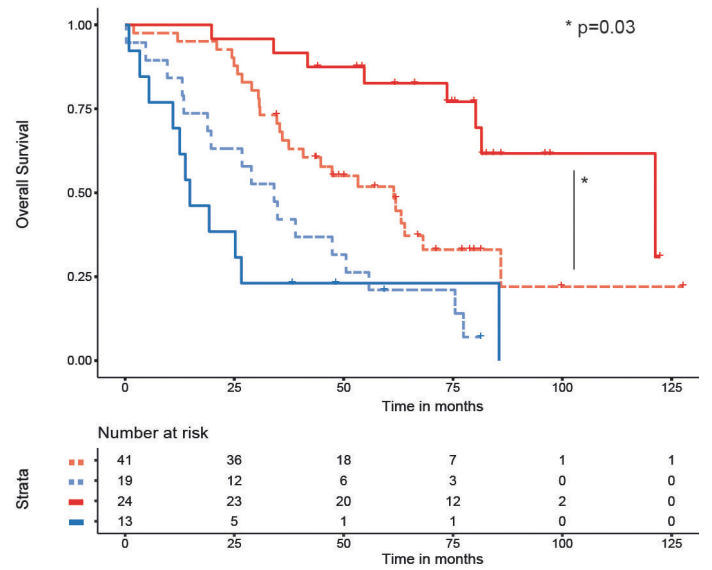

d. Overall Survival NACT cohort

CD8CD103 TRM Stromal infiltration
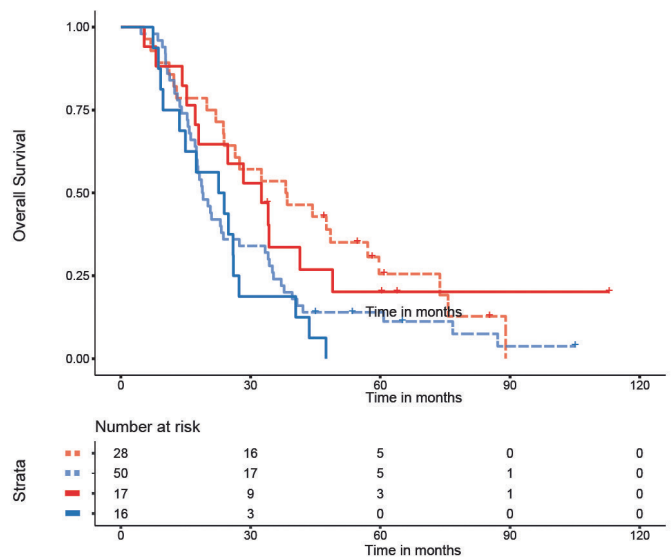

Abstract 263 Figure 2 Prognostic benefit of stomal and epithellial CD8CD103 TRM infiltration in patient subgroups

prognostic stratification of HGSOC patients and may contribute to personalized treatment strategies in the future.

\section{BIOMARKER-BASED EARLY DETECTION OF EPITHELIAL OVARIAN CANCER BASED ON A FIVE-PROTEIN SIGNATURE IN PATIENT'S PLASMA - A PROSPECTIVE TRIAL}

${ }^{1} \mathrm{D}$ Eichkorn* ${ }^{*}{ }^{2} \mathrm{~A}$ Hasenburg, ${ }^{3} \mathrm{~F}$ Vosshagen, ${ }^{4} \mathrm{E}$ Obermayr, ${ }^{5} \mathrm{~A}$ Geroldinger, ${ }^{6} \mathrm{R}$ Zeillinger, ${ }^{7} \mathrm{M}$ Bossart. ${ }^{1}$ Schwarzwald-Baar Clinics, Department of Obstetrics and Gynecology, Villingen-Schwenningen, Germany; ${ }^{2}$ University Medical Center Mainz, Department of Obstetrics and Gynecology, Mainz, Germany; ${ }^{3}$ Ortenau Clinics, Department of Anesthesiology, Lahr/Schwarzwald, Germany; ${ }^{4}$ Medical University of Vienna, Department of Obstetrics and Gynecology, Wien, Austria; ${ }^{5}$ Medical University of Vienna, Section for Clinical Biometrics, Center for Medical Statistics, Wien, Austria; ${ }^{6}$ Medical University of Vienna, Department of Obstetrics and Gynecology, Vienna, Austria; 'St. Josefskrankenhaus, Freiburg, Obstetrics, Gynecology and Gynecologic Oncology, Freiburg im Breisgau, Germany

10.1136/ijgc-2021-ESG0.371

Introduction/Background* Trial on five plasma biomarkers (CA125 - cancer antigen 125, HE4 - human epididymis protein 4, OPN - osteopontin, leptin, prolactin) and their possible role in differentiating benign from malignant ovarian tumors.

Methodology In this unicentric prospective trial preoperative blood samples of 43 women with ovarian masses determined for ovarian surgery were analyzed. 25 patients had pathologically confirmed benign, 18 malignant ovarian tumors. Blood plasma was analyzed for CA125, HE4, OPN, leptin, prolactin and MIF (macrophage migration inhibitory factor) by multiplex immunoassay analysis. Each single protein and a logistic regression model including all the listed proteins were tested as preoperative predictive marker for suspect ovarian masses.

Result(s)* Plasma CA125 was confirmed as a highly accurate tumor marker in ovarian cancer. HE4, OPN, leptin and prolactin plasma levels differed significantly between benign and malignant ovarian masses. With a logistic regression model a formula including CA125, HE4, OPN, leptin and prolactin was developed to predict malignant ovarian tumors. With a discriminatory AUC (area under the curve) of 0.96 it showed to be a highly sensitive and specific diagnostic test for a malignant ovarian tumor. 


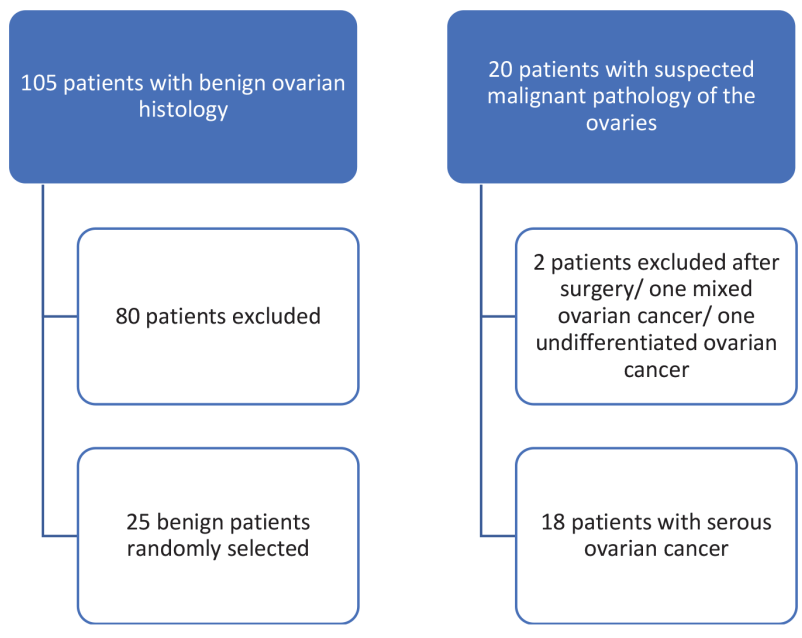

Abstract 266 Figure 1 Patient recruitment. Patients were recruited from the Department of Gynecology at Freiburg University Hospital between July 2013 and July 2015. Data and samples of 43 of the patients were analyzed with an age range of 19 to 81 years

Conclusion* The calculated formula with the combination of CA125, HE4, OPN, leptin and prolactin plasma levels surpasses each single marker in its diagnostic value to discriminate between benign and malignant ovarian tumors. The formula, applied to our patient population was highly accurate but should be validated in a larger cohort.

\section{OUTCOME QUALITY STANDARDS IN ADVANCED OVARIAN CANCER SURGERY}

1,2A Serra*, 1,2MT Climent, ${ }^{1} \mathrm{~A}$ Llueca. ${ }^{1}$ Hospital General Universitari de Castelló, Castelló de la Plana, Spain; ${ }^{2}$ Jaume I University, Castelló de la Plana, Spain

\subsection{6/ijgc-2021-ESG0.372}

Introduction/Background* Advanced ovarian cancer surgery (AOCS) frequently results in serious postoperative complications. Because managing AOCS is difficult, some standards need to be established that allow surgeons to assess the quality of treatment provided and consider what aspects should improve. This study aimed to identify quality indicators (QIs) of clinical relevance and to establish their acceptable quality limits (i.e., standard) in AOCS.

Methodology We performed a systematic search on clinical practice guidelines, consensus conferences, and reviews on the outcome and quality of AOCS to identify which QIs have clinical relevance in AOCS. We then searched the literature (from January 2006 to December 2018) for each QI in combination with the keywords of advanced ovarian cancer, surgery, outcome, and oncology. Standards for each QI were determined by statistical process control techniques. The acceptable quality limits for each QI were defined as being within the limits of the $99.8 \%$ interval, which indicated a favorable outcome.

Result(s)* A total of 38 studies were included. The QIs selected for AOCS were complete removal of the tumor upon visual inspection (complete cytoreductive surgery), a residual tumor of $<1 \mathrm{~cm}$ (optimal cytoreductive surgery), a residual tumor of $>1 \mathrm{~cm}$ (suboptimal cytoreductive surgery), major morbidity, and 5-year survival. The rates of complete cytoreductive surgery, optimal cytoreductive surgery, suboptimal cytoreductive surgery, morbidity, and 5- year survival had quality limits of $<27 \%$, < 23\%, > 39\%, > 33\%, and < $27 \%$, respectively.

Conclusion* Our results provide a general view of clinical indicators for AOCS. Acceptable quality limits that can be considered as standards were established.

\section{VALIDATION OF THREE PREDICTIVE MODELS FOR SUBOPTIMAL CYTOREDUCTIVE SURGERY IN ADVANCED OVARIAN CANCER}

${ }^{1,2} \mathrm{MT}$ Climent* ${ }^{*}{ }^{1,2} \mathrm{~A}$ Serra, ${ }^{1,2} \mathrm{~A}$ Llueca. ${ }^{1}$ Hospital General Universitari de Castelló, Castelló de la Plana, Spain; ${ }^{2}$ Jaume I University, Castelló de la Plana, Spain

\subsection{6/ijgc-2021-ESG0.373}

Introduction/Background* The standard treatment for advanced ovarian cancer (AOC) is cytoreduction surgery and adjuvant chemotherapy. Tumor volume after surgery is a major

\section{Complete cytoreductive surgery (CCS) rate (P-chart).}

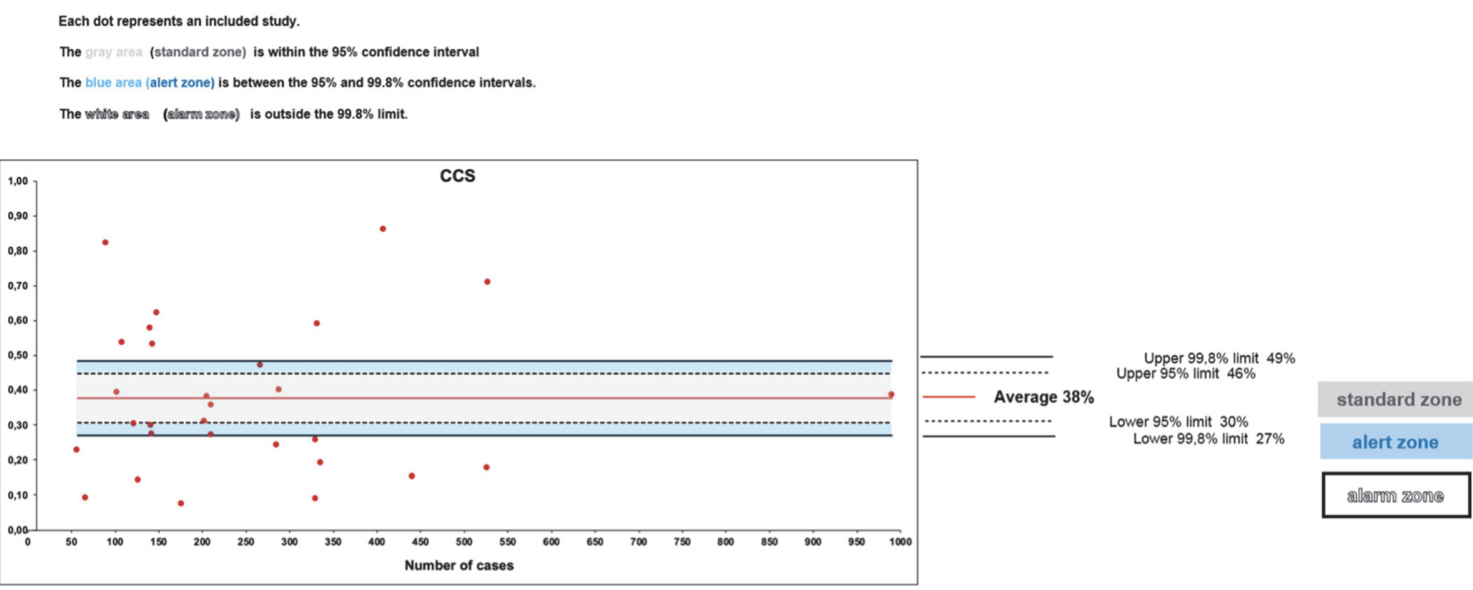

Abstract 267 Figure 1 Complete cytoreductive surgery (CCS) rate (P-chart). Each dot represents an included study. The gray area (standard zone) is within the $95 \%$ confidence interval, the blue are (alert zone) is between the $95 \%$ and $99.98 \%$ confidence intervals, and the white area (alarm zone) is outside the $99.8 \%$ limit 